\title{
Is Low-Dose Haloperidol Effective against Postoperative Nausea and Vomiting? A Randomized Controlled Trial
}

\author{
Mehmet Tevfik Dağa Ebru Tarıkçı Kılıç ${ }^{b} \quad$ Ali Muhittin Taşdoğan ${ }^{c}$ \\ a Department of Anesthesiology and Perioperative Medicine, Yeditepe University, Medical Faculty, Ataşehir, Turkey; \\ ${ }^{b}$ Department of Anesthesiology and Perioperative Medicine, Ümraniye Training and Research Hospital, Ümraniye, \\ Turkey; ' Department of Anesthesiology, SEV American Hospital, Gaziantep, Turkey
}

\section{Keywords}

Haloperidol · Nausea - Vomiting • Patient satisfaction •

Side effects

\begin{abstract}
Background: Nausea and vomiting are undesirable outcomes during the postoperative period. Vomiting may cause life-threatening pulmonary aspiration, as the airway reflex may not be fully restored postoperatively due to the residual effects of anesthetic and analgesic medications. Objective: The aim of this study is to determine the effective dosage of haloperidol against nausea and vomiting, as well as its adverse effects. Materials and Methods: A total of 250 female patients between the ages of 19 and 70, who were admitted for laparoscopic abdominal hysterectomy, were included in this study. The patients were randomized into five groups: placebo $(n=50)$ (Group I), haloperidol $2 \mathrm{mg}(n=$ 50) (Group II), haloperidol $1 \mathrm{mg}(n=50)$ (Group III), haloperidol $0.5 \mathrm{mg}(n=50)$ (Group IV), and haloperidol $0.25 \mathrm{mg}(n=$ 50) (Group V). The patients' duration of anesthesia, duration of surgery, and nausea/vomiting scores were recorded, along with the antiemetic agents used. The Aldrete's recovery scale was used as the postoperative recovery criteria.
\end{abstract}

Data from the following variables were recorded for all patients at postoperative minute 30 and hours 1, 2, 3, 4, 6, 12, and 24: heart rate, systolic arterial pressure, diastolic arterial pressure, level of sedation, visual analog scale values, antiemetic need, patient satisfaction, side effects. Results: It was determined that $0.5,1$, and $2 \mathrm{mg}$ doses of haloperidol were effective in preventing nausea and vomiting, and there was no difference in effectiveness between the $0.25 \mathrm{mg}$ dose group and placebo. Conclusion: Haloperidol was found to be an effective agent against nausea and vomiting at a dose of $0.5 \mathrm{mg}$ and can be administered at the doses of $0.5 \mathrm{mg}$ to $2 \mathrm{mg}$.

(c) 2019 The Author(s)

Published by S. Karger AG, Basel

\section{Introduction}

Nausea, which can occur in isolation or be accompanied by vomiting, is a subjectively discomforting condition. It is also one of the most commonly observed complications following regional and general anesthesia [1, $2]$. Persistent nausea and vomiting can lead to dehydration and electrolyte imbalance, both of which may delay patient discharge following same-day surgeries. Repeated

\section{KARGER}

E-Mail karger@karger.com www.karger.com/dmj

\section{(c) 2019 The Author(s) \\ Published by S. Karger AG, Basel \\ Karge \\ Open access}

This article is licensed under the Creative Commons AttributionNonCommercial-NoDerivatives 4.0 International License (CC BYNC-ND) (http://www.karger.com/Services/OpenAccessLicense). Usage and distribution for commercial purposes as well as any distribution of modified material requires written permission.
Ebru Tarıkçı Kılıç

Department of Anesthesiology and Perioperative Medicine

Ümraniye Training and Research Hospital

Elmalıkent Street, Ümraniye no: 1, İstanbul (Turkey)

E-Mail ebru.tarkc@yahoo.com 
vomiting can increase venous pressure, which may increase bleeding under the skin flap. Since the residual effect of anesthetics can result in depression of the airway reflex, postoperative vomiting is also associated with a high risk of pulmonary aspiration $[3,4]$.

Anatomical studies have shown that the reticular formation is the primary motor pathway for both the visceral and somatic effects of vomiting. This area is located within the lateral formation, which is situated very closely to the tractus solitarius in the brain stem. Electrical stimulation of the vomiting center and the tractus solitarius immediately triggers a vomiting reaction [5]. Damage to this center or its removal prevents the vomiting reaction caused by apomorphine and direct chemical stimulation. Stimulation of other areas within the central nervous system can also affect the vomiting center. These stimuli may involve the afferents originating from the chemoreceptor trigger zone (CTZ) found in the high cortical centers and the area postrema. Other stimuli from the pharynx, gastrointestinal tract, and the mediastinum may also impact on the vomiting center. The area postrema in the brain stem contains receptors for dopamine, opioids, serotonin, and 5-hydroxytryptamine, while the nucleus tractus solitarius is rich in enkephalin receptors as well as histaminic and muscarinic cholinergic receptors. These receptors play an important role in transmitting stimuli to the vomiting center $[4,5]$.

The CTZ is a chemoreceptor area found in the area postrema, on the floor of the brain's fourth ventricle. This is an area outside the blood-brain barrier. The CTZ functions as a station which transmits all of the sensory stimuli coming from the central nervous system and most of the stimuli coming from the periphery to the vomiting center. The vomiting center is found on the floor of the fourth ventricle, immediately next to the CTZ [6].

Nausea and vomiting are affected by patient-related factors such as age, sex, obesity, anxiety gastroparesis, and surgery-related factors including the duration of surgery, the anesthetics used, the methods used to induce anesthesia, postoperative pain, anticholinesterases, and opioids used [7].

Butyrophenones are neuroleptics discovered by Janssen toward the end of the 1950s. They are pharmacologically similar to piperazine compounds and possess strong antipsychotic effects. While they exert sedative effects, they have no anticholinergic effects. Droperidol and haloperidol are two neuroleptic agents with both antiemetic and antidopaminergic effects [8]. The effects of haloperidol begin strongly following its administration and last for about $3 \mathrm{~h}$.
Büttner et al. [9] conducted a meta-analysis on "haloperidol's minimal effective dose" for nausea and vomiting. They reported haloperidol parenteral single doses between 1 and $2 \mathrm{mg}$ as efficacious, with minimal toxicity.

Our aim in this study is to investigate the effectiveness of haloperidol, a butyrophenone derivate, on nausea and vomiting, its optimum dose, and side effects.

\section{Materials and Methods}

Following the approval of the study by the ethics committee, written informed consent was obtained from all of patients participating in the study. This randomized clinical trial study was conducted on 250 female patients aged between 19 and 70 years, belonging to the American Society of Anesthesiologists (ASA) physical status classification I-II scheduled for laparoscopic abdominal surgery. Patients with lung, liver, kidney, heart, or cranial diseases, patients with planned large intestine resection, patients who had received antiemetics or had nasogastric tubes inserted for any reason $24 \mathrm{~h}$ before the surgery, patients with contraindications for haloperidol, or patients with opioid allergies were all excluded from the study. The Apfel risk score was taken as a basis to ensure standardization between the patients. In accordance with this classification, patients with a risk level of $40 \%$ or greater were selected. This risk score included patients with a history of motion sickness, non-smokers, female, with a history of obesity, who were expected to require opioids, and who experienced nausea and vomiting in previous surgeries. A total of 250 female patients were randomized into five groups using computer-generated codes numbered in opaque envelopes: Group I $(n=50)$, the control group; Group II $(n=50)$, the $2 \mathrm{mg}$ haloperidol group; Group III $(n=50)$, the $1 \mathrm{mg}$ haloperidol group; Group IV ( $n$ $=50)$, the $0.5 \mathrm{mg}$ haloperidol group; and Group $\mathrm{V}(n=50)$, the 0.25 $\mathrm{mg}$ haloperidol group. A nurse not involved in the treatment opened the envelopes and prepared the study drugs. Patients and anesthesiologists who participated in the study were blinded to the groups. Postoperative evaluations were conducted by a group of evaluators who were blind to the study groups.

All participating patients fasted for $8 \mathrm{~h}$ before surgery. A 0.05 $\mathrm{mg} / \mathrm{kg}$ dose of midazolam was administered intramuscularly as premedication, $45 \mathrm{~min}$ before the surgery.

When the patients were taken to the operating room, an intravenous vascular access was established with an 18-gauge cannula on the back of their hands. An infusion of isotonic saline solution at a rate of $10 \mathrm{~mL} / \mathrm{kg} / \mathrm{h}$ was then started.

Cardiac rhythm and heart rate were monitored using three lead ECGs, while systolic arterial pressure (SAP) and diastolic arterial pressure (DAP) were measured noninvasively. Peripheral oxygen saturation was monitored using a pulse oximeter.

Anesthesia induction was performed by administering $2 \mathrm{mg} / \mathrm{kg}$ propofol and $2 \mu \mathrm{g} / \mathrm{kg}$ fentanyl intravenously. A $0.6 \mathrm{mg} / \mathrm{kg}$ dose of rocuronium was used as a neuromuscular blocker. Endotracheal intubation was carried out once sufficient neuromuscular block was ensured. Mechanical ventilation was initiated with a tidal volume of $8 \mathrm{~mL} / \mathrm{kg}$ and a frequency of 12 breaths $/ \mathrm{min}$. Anesthesia was maintained with $2 \%$ sevoflurane and $50 \% \mathrm{O}_{2} / \mathrm{N}_{2} \mathrm{O}(2 \mathrm{~L} / \mathrm{min})$. At the end of surgery, all patients received atropine $(0.02 \mathrm{mg} / \mathrm{kg})$ and neostigmine $(0.04 \mathrm{mg} / \mathrm{kg})$. During the period of the skin closure, Group I 
Table 1. Clinical presentation and demographic parameters

\begin{tabular}{|c|c|c|c|c|c|c|c|}
\hline Variable & $\begin{array}{l}\text { Group I } \\
(n=50)\end{array}$ & $\begin{array}{l}\text { Group II } \\
(n=50)\end{array}$ & $\begin{array}{l}\text { Group III } \\
(n=50)\end{array}$ & $\begin{array}{l}\text { Group IV } \\
(n=50)\end{array}$ & $\begin{array}{l}\text { Group V } \\
(n=50)\end{array}$ & $p^{\mathrm{a}}$ & $\mathrm{U}^{\mathrm{b}}$ \\
\hline Age, years & $47(32-76)$ & $42.5(32-68)$ & $38(32-76)$ & $42(32-69)$ & $43.0(32-69)$ & 0.218 & - \\
\hline Weight, kg & $71(66-74)$ & $77.0(57-89)$ & $70.0(65-74)$ & $72.0(66-88)$ & $72.0(66-86)$ & 0.0001 & $\begin{array}{l}2>1,3,4,5 \\
1>5 \\
4,5>3\end{array}$ \\
\hline Duration of anesthesia, min & $120.0(100-140)$ & $120.0(100-140)$ & $120.0(100-140)$ & $129.0(100-148)$ & $120.0(100-140)$ & 0.0001 & $4>1,2,3,5$ \\
\hline Operative time, min & $109(100-121)$ & $109.0(100-126)$ & $109.0(100-121)$ & $110(100-130)$ & $110.0(100-121)$ & 0.091 & - \\
\hline
\end{tabular}

Values presented as median (range). ${ }^{a}$ Kruskal-Wallis test. ${ }^{b}$ Post hoc test for significant differences (Mann-Whitney U test) at 0.01 alpha correction.

patients did not receive any antiemetics, while Group II patients received $2 \mathrm{mg}$ of haloperidol, Group III patients received $1 \mathrm{mg}$ haloperidol, Group IV patients received $0.5 \mathrm{mg}$ haloperidol, and Group $\mathrm{V}$ patients received $0.25 \mathrm{mg}$ haloperidol. At this stage, $2 \mathrm{mg}$ morphine was administered as an intravenous bolus for postoperative analgesia. For patient-controlled analgesia, $30 \mathrm{mg}$ of morphine $\mathrm{HCl}$ was added to $100 \mathrm{~mL}$ of isotonic saline solution and was administered. A patient-controlled analgesic device was used, with the basal infusion programmed to $2 \mathrm{mg} / \mathrm{h}$, the lock-out period set to $20 \mathrm{~min}$, and the 4-hour limit set to $20 \mathrm{mg}$. Following surgery, total duration of surgery, duration of anesthesia, and postoperative fingertip blood sugar values were recorded. The recovery of patients was assessed using the Aldrete's recovery criteria. During this assessment, the scores assigned to each case were summed, and a total score of 10 points was considered as full recovery. These criteria were repeated at minutes 5, 15, and 30. The Ramsay sedation scale was used to determine the degree of sedation. Patient satisfaction, time of flatulence, time of oral intake, time of mobilization, the application of the Lyles Quality of Recovery survey, postoperative blood sugar values, duration of hospitalization, and side effects were all recorded. Lyles Quality of Recovery questionnaire consists of 40 statements. The responses for the positive statements were on a five-Likert scale, where $5=$ all of the time, $4=$ most of the time, $3=$ usually, $2=$ some of the time, $1=$ never. The responses for the negative statements were on a five-Likert scale where $5=$ never, $4=$ some of the time, $3=$ usually, $2=$ most of the time, $1=$ all of the time. The total score of the scale is 200. The total score for the whole scale was calculated for every patient. Then the mean of the total score for all patients was calculated. The highest score indicates positive excellent quality of recovery from surgery, while the lowest score indicates poor quality of recovery. At postoperative minute 30 and hours 1, 2, 4, 6, 12, 16, and 24 , the following information was recorded for all of the patients: heart rate, SAP, DAP, number of breaths per minute, visual analog scale (VAS) sedation degrees, patient satisfaction, and the presence/ absence of side effects. Patient satisfaction was considered poor with scores of $0-25$, fair with scores of 26-50, good with scores of 51-75, and very good with scores of 76-100.

Prior to the surgery, all of the patients were informed that they might experience nausea and vomiting during the postoperative period. They were informed about the medications that can be used to prevent this. Methods for questioning and evaluating nausea and sedations scores are described below.

Nausea scores were defined as $0=$ no nausea and $1=$ nausea. Patients were explained that they would be asked to assign a number for their nausea and vomiting. In case of vomiting, a score of 1 was assigned, while a score of 0 was assigned in the absence of vomiting.

Patients were also informed that the sedation scores would be assigned as follows: 5 = patient does not respond to painful stimuli; 4 = patient only responds to painful stimuli; 3 = patient does not respond to verbal commands, but responds to shaking and tactile stimuli; 2 = patient only responds to repeated and loud commands; 1 = patient is sedated yet oriented, normal response to verbal commands; 0 = patients is awake.

The patients were transferred to their wards when their vital signs were deemed adequate and their Aldrete's score was at least 9. On the day following the surgery, the patients' additional antiemetic needs in the postoperative $24 \mathrm{~h}$ were recorded. In cases where the patients vomited and/or had nausea, or requested additional antiemetics, they were intravenously administered with $8 \mathrm{mg}$ ondansetron, and the occurrence of such an administration was recorded.

\section{Statistics}

Parameters analyzed in the research were described using mean and standard deviations. Before difference analysis, normality tests were performed using Kolmogorov-Smirnov test with Lilliefors correction. Since all parameters were non-normally distributed, nonparametric tests were used. Kruskal-Wallis test was used for comparison of more than two groups. For significant differences, Mann-Whitney U test was used for post hoc tests with alpha correction using Monte Carlo test. Chi-square test was used for differences of categorical variables. Since analyses were nonparametric, alpha or Bonferroni corrections were not used for post hoc tests. All analyses were performed at SPSS 17.0 for windows program with $95 \%$ confidence level.

\section{Results}

Mean age was found to be 47 years (32-76) in Group I, 42.5 years (32-68) in Group II, 38 years (32-76) in Group III, 42 years (32-69) in Group IV, 43 years (32-69) in Group V $(p=0.218)$. Weight was found to be $71 \mathrm{~kg}$ (66-74) in Group I, 77 kg (57-89) in Group II, 70 kg (65$74)$ in Group III, $72 \mathrm{~kg}$ (66-88) in Group IV, $72 \mathrm{~kg}$ (66$86)$ in Group V $(p=0.0001)$. 
Table 2. Sedation scores

\begin{tabular}{cllllll}
\hline & $\begin{array}{l}\text { Group I } \\
(n=50)\end{array}$ & $\begin{array}{l}\text { Group II } \\
(n=50)\end{array}$ & $\begin{array}{l}\text { Group III } \\
(n=50)\end{array}$ & $\begin{array}{l}\text { Group IV } \\
(n=50)\end{array}$ & $\begin{array}{l}\text { Group V } \\
(n=50)\end{array}$ & $p^{\mathrm{a}, \mathrm{b}}$ \\
\hline $30 \mathrm{~min}$ & $2.0(1-3)$ & $2.0(1-3)$ & $2.0(1-3)$ & $2.0(1-4)$ & $2.0(1-3)$ & 0.997 \\
$1 \mathrm{~h}$ & $2.0(1-3)$ & $2.0(1-3)$ & $2.0(1-3)$ & $2.0(1-3)$ & $2.0(1-3)$ & 0.798 \\
$2 \mathrm{~h}$ & $2.0(1-3)$ & $2.0(1-3)$ & $2.0(1-3)$ & $2.0(1-4)$ & $2.0(1-3)$ & 0.995 \\
$4 \mathrm{~h}$ & $2.0(1-3)$ & $2.0(1-3)$ & $2.0(1-3)$ & $2.0(1-3)$ & $2.0(1-3)$ & 0.944 \\
$8 \mathrm{~h}$ & $2.0(1-3)$ & $2.0(1-3)$ & $2.0(1-3)$ & $2.0(1-3)$ & $2.0(1-4)$ & 0.999 \\
$12 \mathrm{~h}$ & $2.0(1-3)$ & $2.0(1-3)$ & $2.0(1-3)$ & $2.0(1-3)$ & $2.0(1-3)$ & 0.880 \\
$16 \mathrm{~h}$ & $2.0(1-3)$ & $2.0(1-3)$ & $2.0(1-3)$ & $2.0(1-3)$ & $2.0(1-3)$ & 0.992 \\
$24 \mathrm{~h}$ & $2.0(1-3)$ & $2.0(1-3)$ & $2.0(1-4)$ & $2.0(1-3)$ & $2.0(1-3)$ & 0.996 \\
\hline
\end{tabular}

Values presented as median (range). ${ }^{a}$ Kruskal-Wallis test. ${ }^{b}$ Since differences between groups were insignificant, post hoc tests were not used. Sedation scores for all time intervals were not significantly different between groups $(p>0.05)$. Thus, post hoc test was not needed.

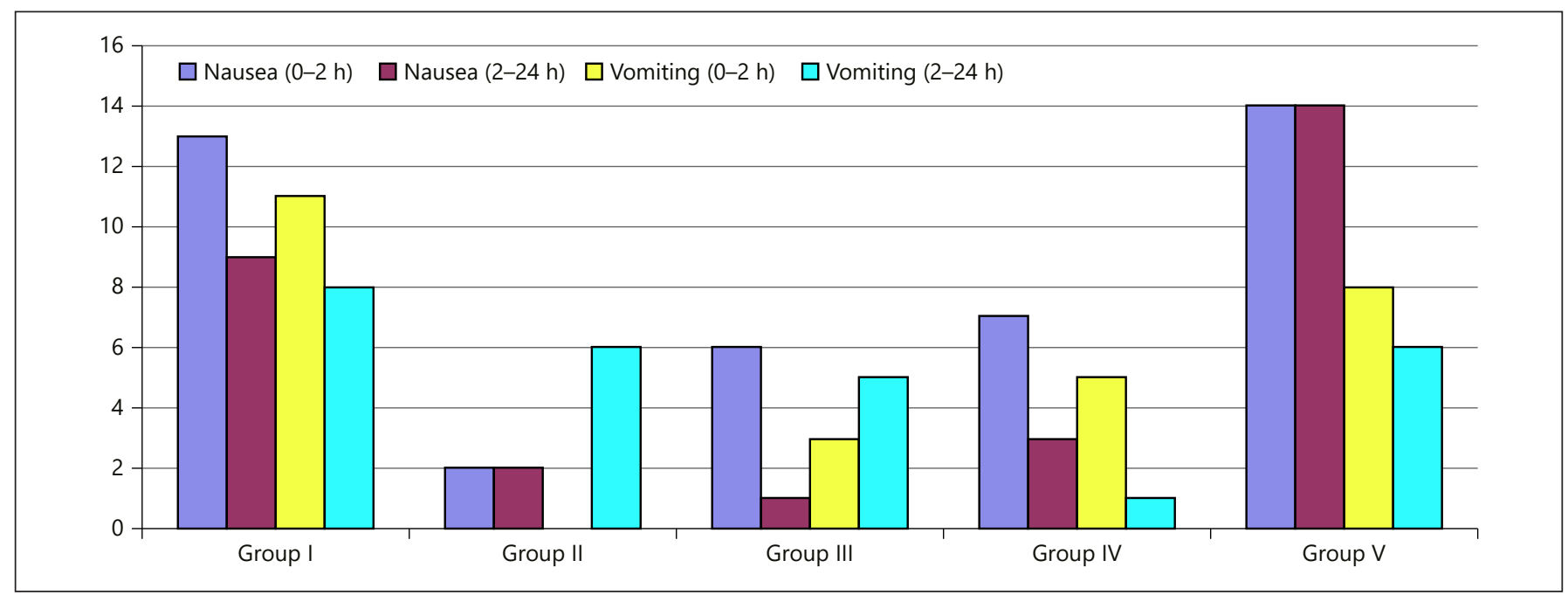

Fig. 1. Comparison of nausea and vomiting scores between the groups.

Duration of anesthesia was found to be $120 \mathrm{~min}$ (100140 ) in Group I, 120 min (100-140) in Group II, 120 min (100-140) in Group III, 129 min (100-148) in Group IV, 120 min $(100-140)$ in Group V $(p=0.0001)$. Operative time did not differ statistically between the groups $(p=0.091)$ (Table 1). Post hoc Mann-Whitney U test was performed in order to understand the reason for the differences.

Heart rates, SAP, and DAP of the patients in all five groups were compared at minute 30 and at hours 1, 2, 4, 6, 12,16 , and 25 after surgery. No significant differences were identified for these values among all the groups $(p>0.05)$.

The sedation scores for the five groups were compared at minute 30 and at hours 1, 2, 4, 6, 12, 16 and 25, and no significant difference was identified for the values among these groups for all time intervals $(p>0.05)$ (Table 2). Thus, post hoc test was not needed.

Assessment of nausea among the patients during the initial $2 \mathrm{~h}$ after surgery revealed that $13(26 \%)$ patients in Group I, 2 (4\%) patients in Group II, 7 (14\%) patients in Group III, 7 (14\%) patients in Group IV, and 14 (28\%) patients in Group V had nausea during this period. Statistical comparisons between the groups indicated significant statistical difference $(p>0.008)$ (Fig. 1; Table 3).

Assessment of nausea among the patients in the 2 to $24 \mathrm{~h}$ following surgery revealed the presence of nausea in $9(18 \%)$ patients in Group I, 2 (4\%) patients in Group II, 1 (2\%) patient in Group III, 3 (6\%) patients in Group IV, and $14(28 \%)$ patients in Group V. Statistical comparison 
Table 3. Nausea and vomiting scores

\begin{tabular}{lrlllll}
\hline & $\begin{array}{c}\text { Group I } \\
(n=50)\end{array}$ & $\begin{array}{l}\text { Group II } \\
(n=50)\end{array}$ & $\begin{array}{l}\text { Group III } \\
(n=50)\end{array}$ & $\begin{array}{l}\text { Group IV } \\
(n=50)\end{array}$ & $\begin{array}{l}\text { Group V } \\
(n=50)\end{array}$ & $p^{\mathrm{a}}$ \\
\hline Nausea 0-2 h & $13(26.0)$ & $2(4.0)$ & $7(14.0)$ & $7(14.0)$ & $14(28.0)$ & 0.008 \\
Nausea 2-24 h & $9(18.0)$ & $2(4.0)$ & $1(2.0)$ & $3(6.0)$ & $14(28.0)$ & 0.000 \\
Vomiting 0-2 h & $10(20.0)$ & - & $3(6.0)$ & $5(10.0)$ & $8(16.0)$ & 0.009 \\
Vomiting 2-24 h & $8(16.0)$ & $6(12.0)$ & $5(10.0)$ & $1(2.0)$ & $6(12.0)$ & 0.218 \\
\hline
\end{tabular}

Values presented as $n(\%) .{ }^{\text {a }}$ Chi-square test, differences over $5 \%$ are significant.

Table 4. VAS scores

\begin{tabular}{ccllllll}
\hline & $\begin{array}{l}\text { Group I } \\
(n=50)\end{array}$ & $\begin{array}{l}\text { Group II } \\
(n=50)\end{array}$ & $\begin{array}{l}\text { Group III } \\
(n=50)\end{array}$ & $\begin{array}{l}\text { Group IV } \\
(n=50)\end{array}$ & $\begin{array}{l}\text { Group V } \\
(n=50)\end{array}$ & $p^{\mathrm{a}}$ & $\mathrm{U}^{\mathrm{b}}$ \\
\hline $30 \mathrm{~min}$ & $3.0(2-4)$ & $3.0(2-4)$ & $3.0(2-4)$ & $3.0(2-4)$ & $3.0(2-4)$ & 0.738 & - \\
$1 \mathrm{~h}$ & $3.0(2-4)$ & $3.0(2-4)$ & $3.0(2-4)$ & $2.0(2-4)$ & $3.0(2-4)$ & 0.001 & $1,2,3,5>4$ \\
$2 \mathrm{~h}$ & $2.0(2-3)$ & $2.0(2-3)$ & $2.0(2-3)$ & $2.0(2-3)$ & $2.0(2-3)$ & 0.043 & - \\
$4 \mathrm{~h}$ & $2.0(1-2)$ & $2.0(1-2)$ & $2.0(1-2)$ & $2.0(1-2)$ & $2.0(1-2)$ & 0.783 & - \\
$8 \mathrm{~h}$ & $1.0(1-2)$ & $1.0(1-2)$ & $1.0(1-2)$ & $1.0(0-2)$ & $1.0(1-2)$ & 0.985 & - \\
$12 \mathrm{~h}$ & $1.0(1-2)$ & $1.0(1-2)$ & $1.0(1-2)$ & $1.0(0-2)$ & $1.0(1-2)$ & 0.131 & - \\
$16 \mathrm{~h}$ & $1.0(0-2)$ & $1.0(0-1)$ & $1.0(0-1)$ & $1.0(0-1)$ & $1.0(0-1)$ & 0.254 & - \\
$24 \mathrm{~h}$ & $0.0(0-1)$ & $0.0(0-1)$ & $0.0(0-1)$ & $0.0(0-1)$ & $0.0(0-1)$ & 0.913 & - \\
\hline
\end{tabular}

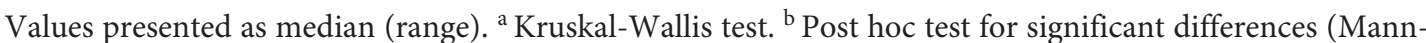
Whitney $\mathrm{U}$ test) at 0.01 alpha correction.

of these groups showed a significant difference $(p=0.000)$ (Fig. 1; Table 3).

Assessment of vomiting scores among the patients in the initial $2 \mathrm{~h}$ after surgery revealed that $10(20 \%)$ patients in Group I, $0(0 \%)$ patient in Group II, 3 (6\%) patients in Group III, 5 (10\%) patients in Group IV, and 8 (16\%) patients in Group V had vomiting during this period. Statistical comparison between the groups indicated a significant difference between them $(p=0.009)$ (Fig. 1; Table 3).

Assessment of vomiting among the patients in the 2 to $24 \mathrm{~h}$ following surgery revealed the presence of vomiting in $8(16 \%)$ patients in Group I, $6(12 \%)$ patients in Group II, 5 (10\%) patients in Group III, 1 (2\%) patient in Group IV, and $6(12 \%)$ patients in Group V. Statistical comparison of these groups showed no significant difference between them ( $p=0.218)$ (Fig. 1).

VAS scores for the five groups were compared at minute 30 and at hours 1, 2, 4, 8, 12, 16, and 24, and analysis results showed that VAS score differences at the first and second hour were statistically significant $(p<0.05)$, whereas all other interval levels did not show any statistically significant difference $(p>0.05)$. Post hoc test results showed that first
Table 5. Aldrete score

\begin{tabular}{lc}
\hline Criteria & Score \\
\hline 1. Activity & 2 \\
Moves all extremities & 1 \\
Moves two extremities & 0 \\
Unable to move extremities & 2 \\
\hline 2. Respiration & 1 \\
Breathes deeply, coughs freely & 0 \\
Dyspneic, shallow or limited breathing & \\
Apneic & 2 \\
\hline 3. Circulation (blood pressure) & 1 \\
$20 \% \pm$ preanesthetic level & 0 \\
$20-49 \% \pm$ preanesthetic level & 2 \\
$50 \% \pm$ preanesthetic level & 1 \\
\hline 4. Consciousness & 0 \\
Fully awake & \\
Arousable on calling & 2 \\
Not responding $^{-}$ & \\
\hline 5. Oxygen saturation & 0 \\
SpO $>92 \%$ on room air & \\
Supplemental oxygen requirement to maintain $\mathrm{SpO}_{2}>90 \%$ & 1 \\
$\mathrm{SpO}_{2}<90 \%$ with oxygen supplementation & \\
\hline
\end{tabular}




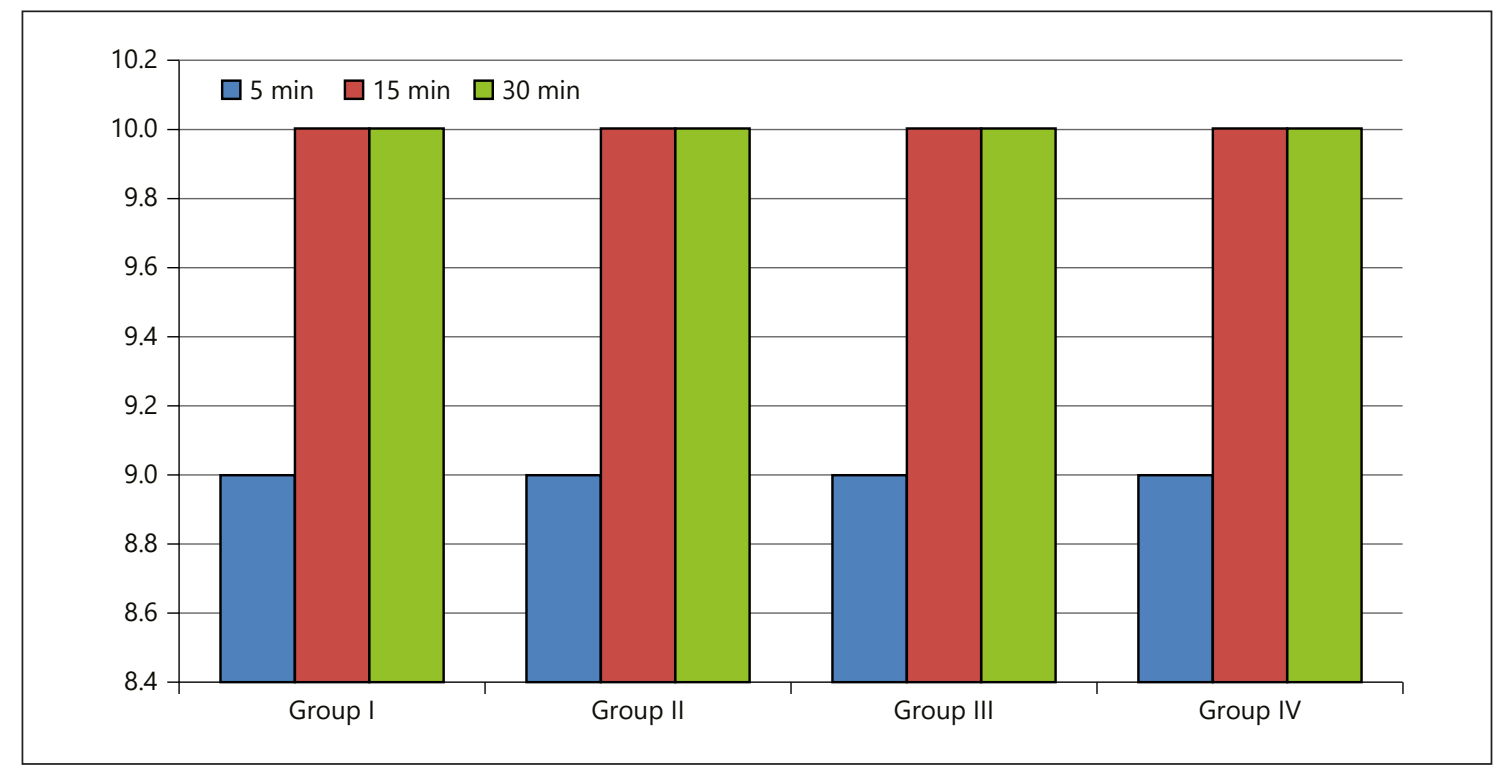

Fig. 2. Aldrete scores of the patients.

Table 6. Postoperative values

\begin{tabular}{|c|c|c|c|c|c|c|c|}
\hline & $\begin{array}{l}\text { Group I } \\
(n=50)\end{array}$ & $\begin{array}{l}\text { Group II } \\
(n=50)\end{array}$ & $\begin{array}{l}\text { Group III } \\
(n=50)\end{array}$ & $\begin{array}{l}\text { Group IV } \\
(n=50)\end{array}$ & $\begin{array}{l}\text { Group V } \\
(n=50)\end{array}$ & $p^{\mathrm{a}}$ & $\mathrm{U}^{\mathrm{b}}$ \\
\hline Patient satisfaction & $55.0(34-59)$ & $80.0(60-89)$ & $58.0(30-86)$ & $77.0(55-88)$ & $58.0(40-75)$ & 0.001 & $\begin{array}{l}2>1,3,4,5 \\
3,5>1 \\
4>1,3,5\end{array}$ \\
\hline First flatus, h & $12.38 \pm 0.78$ & $12.04 \pm 0.20$ & $12.42 \pm 0.97$ & $12.20 \pm 0.61$ & $11.80 \pm 0.57$ & 0.001 & $\begin{array}{l}1,3>2,5 \\
2,4>5\end{array}$ \\
\hline First oral intake, $\mathrm{h}$ & $15.0(14-15)$ & $15.0(14-15)$ & $15.0(12-15)$ & $15.0(12-15)$ & $15.0(12-15)$ & 0.931 & - \\
\hline First mobilization, h & $18.0(16-22)$ & $18.0(16-22)$ & $18.0(16-22)$ & $18.0(16-22)$ & $18.0(16-22)$ & 0.688 & - \\
\hline Lyles (quality of recovery) & $12.0(10-18)$ & $12.0(12-20)$ & $12.0(11-22)$ & $12.0(12-20)$ & $12.0(11-22)$ & 0.511 & - \\
\hline Postoperative blood sugar & $133.0(100-166)$ & $133.0(100-166)$ & $133.0(100-166)$ & $133.0(100-166)$ & $133.0(100-166)$ & 0.050 & - \\
\hline Length of hospital stay & $34.78 \pm 0.84$ & $34.58 \pm 1.08$ & $33.86 \pm 1.98$ & $35.90 \pm 1.39$ & $34.78 \pm 0.76$ & 0.001 & $\begin{array}{l}1,2,5>3 \\
4>1,2,3,5\end{array}$ \\
\hline
\end{tabular}

Values presented as median (range) or mean \pm standard deviation. ${ }^{a}$ Kruskal-Wallis test. ${ }^{b}$ Post hoc test for significant differences (Mann-Whitney $\mathrm{U}$ test) at 0.01 alpha correction.

hour VAS score was significantly lower in Group IV compared to all other group differences $(p<0.05)$. for second hour VAS score, Group I had significantly higher score than Group II and Group IV $(p<0.05)$ (Table 4).

Morphine consumption values of patients at postoperative hour 24 were determined as $24.04 \pm 5.05$ for Group I, $23.90 \pm 5.51$ for Group II, $24.03 \pm 5.50$ for Group III, $24.08 \pm 5.45$ for Group IV, and 23.88 \pm 4.92 for Group V. Statistical comparison of the groups revealed no significant differences $(p>0.05)$.

Comparisons were made between the five groups with respect to the patients' modified Aldrete's scores at minutes
5,15 , and 30 post-surgery. No significant differences were identified between these values ( $p>0.05)$ (Fig. 2; Table 5).

Table 6 shows that patient satisfaction and first oral intake were found to be highest in Group II, whereas first flatus was found to be higher in Group III. Length of hospital stay was highest in the Group IV, and other parameters were highest in the Group V. Kruskal-Wallis test results showed that patient satisfaction, first flatus, and length of hospital stay were significantly different $(p<$ 0.05). According to post hoc test results, Group II had significantly higher patient satisfaction than the other groups $(p<0.05)$. Patient satisfaction of Group I was sig- 
Fig. 3. Lyles quality scores.

How have you been feeling in the last 24 hours?

( 0 to 10 , where: 0 - none of the time (poor) and 10 - all of the time (excellent))

1. Able to breathe easily

2. Been able to enjoy food

3. Feeling rested

4. Have had a good sleep

5. Able to look after personal toilet and hygiene unaided

6. Able to communicate with family or friends

7. Getting support from hospital doctors and nurses

8. Able to return to work or usual home activities

9. Feeling comfortable and in control

10. Having a feeling of general goodness

nificantly lower than Group III and Group V $(p<0.05)$. Patient satisfaction of Group IV was higher than Group I, Group III, and Group V $(p<0.05)$. First flatus of Group I and Group III were significantly higher than Group II and Group V $(p<0.05)$. First flatus of Group II and Group IV were significantly higher than Group V $(p<0.05)$. Length of hospital stay was significantly higher in Group I, Group II, and Group V compared to Group III ( $p<$ $0.05)$. Group IV had significantly higher length of hospital stay than all other groups $(p<0.05)$ (Table 6; Fig. 3).

Antiemetic need values for patients between postoperative hours 0 and 24 were determined in $20(40 \%)$ of the patients in Group I, 3 (6\%) of the patients in Group II, 4 $(8 \%)$ of the patients in Group III, 7 (14\%) of the patients in Group IV, and 14 (28\%) of the patients in Group V. Statistical comparison among the groups revealed a significant difference $(p<0.05)$.

None of the groups exhibited any side effects such as cardiac arrhythmias, tardiness, dyskinesia, extrapyramidal reactions, increased salivation, or tremors.

\section{Discussion}

Haloperidol is a powerful antipsychotic drug which has been used in psychiatry as well as for the control of severe emesis. Haloperidol is well established, and this inexpensive drug has been used to control emesis for more than 40 years despite lack of evidence-based data to support its efficacy and determine its optimum dose on postoperative nausea and vomiting (PONV) $[1,2]$. PONV is a serious, common, and distressful complication in patients emerging from general anesthesia. This is particularly common in high-risk patient groups such as females undergoing gynecologic and laparoscopic surgeries who used patient-controlled analgesia with opioids. For anesthesiologists an important goal is determining an appropriate medication for controlling PONV $[1,2,10]$. Despite improvements in new drugs for PONV, it remains an undesirable outcome following general anesthesia. Previous research indicates that up to $30 \%$ of patients who received general anesthesia complained of PONV and delayed discharge from the hospital as a result [11]. Therefore, the methods and dosage of prophylaxis against PONV in high-risk patients should be assessed.

In this randomized study, we compared the doses of haloperidol for PONV and we determined that haloperidol was found to be an effective agent against nausea and vomiting at a starting dose of $0.5 \mathrm{mg}$ and can be administered at the doses of $0.5 \mathrm{mg}$ to $2 \mathrm{mg}$. Patient's satisfaction was higher in the 1- and 2-mg haloperidol groups.

Many studies [12] have investigated haloperidol. In a meta-analysis of 23 randomized trials, the suggested effective dosage of haloperidol to prevent PONV was between 0.5 and $4 \mathrm{mg}$. In several clinical trials [13], the reported antiemetic doses of haloperidol were 1 or $2 \mathrm{mg}$. Joo et al. [10] randomized three study groups to determine the optimum antiemetic dose of haloperidol. At the end of anesthesia, groups were administered saline, 1 , and $2 \mathrm{mg}$ of haloperidol, respectively. This dosage was based on doses used in a 
clinical trial by Dağtekin et al. [14]. PONV scores were significantly lower for patients in the study groups that received haloperidol compared with patients in the placebo group. Dağtekin et al. [14] in their study reported $10 \mu \mathrm{g} / \mathrm{kg}$ haloperidol to be effective in female participants. In another study [15] which tested $5 \mathrm{mg}$ intravenous haloperidol in 1,089 patients with PONV up to $6 \mathrm{~h}$, the incidence of nausea was $16.4 \%$ with haloperidol and $43.8 \%$ with placebo.

In several literature studies, haloperidol was compared with ondansetron. Pradeep et al. [16] in their study compared the efficacy of haloperidol with ondansetron in preventing PONV after laparoscopic abdominal surgeries. They reported that ondansetron $4 \mathrm{mg}$ is not as effective as $2 \mathrm{mg}$ haloperidol for reducing the incidence of PONV. Yazbeck-Karam et al. [17] in another randomized clinical trial compared haloperidol with ondansetron and reported that haloperidol is not inferior to ondansetron for the early treatment of PONV.

Honarmand et al. [18] in their study divided patients into 4 groups. Group $\mathrm{H}$ received haloperidol $2 \mathrm{mg}$ i.v., Group M received midazolam 2 mg i.v., Group HM received haloperidol $2 \mathrm{mg}$ plus $2 \mathrm{mg}$ midazolam, and Group $\mathrm{C}$ received saline as placebo. They observed better results with combined administration of haloperidol and midazolam for reducing PONV in patients undergoing middle ear surgery under general anesthesia.

Aghadavoudi [19] conducted a similar study on PONV after strabismus surgery. They reported the lowest incidence of PONV with the administration of $0.05 \mathrm{mg} / \mathrm{kg}$ haloperidol plus $0.05 \mathrm{mg} / \mathrm{kg}$ midazolam.

Chaparro et al. [20] reported haloperidol's beneficial effects for the prevention of PONV in the first $24 \mathrm{~h}$ postoperatively. In addition, the minimum effective dose was reported as $0.5 \mathrm{mg}$. Raising the dose from $2 \mathrm{mg}$ to $4 \mathrm{mg}$ was used to establish safety. Smaller and single doses should not be associated with serious complications.

Despite haloperidol's long plasma half-life and accompanied opioid patient-controlled analgesia usage, we did not observe any significant differences between the groups with respect to its sedative effects and Aldrete's scores during the recovery period in our study. These findings are similar to those obtained in a study by Chu et al. [21]. Also, they did not report any sedative effects even with $2 \mathrm{mg}$ haloperidol administration compared with saline.

Haloperidol has the potential to cause neurologic adverse effects. Büttner et al. [9] reported that only 1 of 806 patients who received $0.25-5 \mathrm{mg}$ haloperidol i.v experienced extrapyramidal symptoms with a 4-mg dose. In our study, none of the patients showed neurological side effects.

It has been suggested that haloperidol may be cardiotoxic. These drugs at high doses have the potential to prolong the QT interval, thereby carrying the risk for torsades de pointes. We observed no arrhythmia or prolonged QT interval in our study.

In conclusion, haloperidol is antiemetic at doses lower than those used in psychiatric disorders. For the prevention of PONV after surgeries, parenteral single doses between 1 and $2 \mathrm{mg}$ can be used safely. Due to its cost effectiveness it can be an effective alternative to other expensive antiemetic drugs.

\section{Acknowledgement}

No funds or grants were received in support of the manuscript.

\section{Disclosure Statement}

The authors declare that the article content was composed in the absence of any commercial or financial relationships that could be construed as a potential conflict of interest.

\section{Author Contribution}

Dr. Mehmet Tevfik Dağ: conception, analysis, critical analysis, final approval. Dr. Ebru Tarıkçı Kılıç: design, data acquisition, manuscript drafting, final approval. Dr. Ali Muhittin Taşdoğan: data acquisition, critical analysis.

\section{References}

1 Eidi M, Kolahdouzan K, Hosseinzadeh H, Tabaqi R. Comparison of ondansetron vs ondansetron and dexamethasone in the prevention of postoperative nausea and vomiting in patients undergoing surgery with general anesthesia. Iran J Med Sci. 2012;37(3): $166-72$.

2 Ahsan K, Abbas N, Naqvi SM, Murtaza G, Tariq S. Comparison of efficacy of ondansetron and dexamethasone combination and ondansetron alone in preventing postopera- tive nausea and vomiting after laparoscopic cholecystectomy. J Pak Med Assoc. 2014 Mar; 64(3):242-6.

3 Rose JB, Watcha MF. Postoperative Nausea and Vomiting in Anesthesia \& perioperative complications. 2nd ed. 1999. pp. $425-$ 40.

4 Rüsch D, Eberhart LH, Wallenborn J, Kranke $P$. Nausea and vomiting after surgery under general anesthesia: an evidence-based review concerning risk assessment, prevention, and treatment. Dtsch Arztebl Int. 2010 Oct 107(42):733-41.

5 Chapter 16. In: Ronald D. Miller. Miller's Anesthesia. PONV; 2015.

6 Ahsan K, Abbas N, Naqvi SM, Murtaza G, Tariq S. Comparison of efficacy of ondansetron and dexamethasone combination and ondansetron alone in preventing postoperative nausea and vomiting after laparoscopic cholecystectomy. J Pak Med Assoc. 2014 Mar; 64(3):242-6. 
7 Apfel CC, Heidrich FM, Jukar-Rao S, Jalota L, Hornuss C, Whelan RP, et al. Evidence-based analysis of risk factors for postoperative nausea and vomiting. Br J Anaesth. 2012 Nov; 109(5):742-53.

8 Benevides ML, Oliveira SS, de Aguilar-Nascimento JE. The combination of haloperidol, dexamethasone, and ondansetron for prevention of postoperative nausea and vomiting in laparoscopic sleeve gastrectomy: a randomized double-blind trial. Obes Surg. 2013 Sep; 23(9):1389-96.

9 Büttner M, Walder B, von Elm E, Tramèr MR. Is low-dose haloperidol a useful antiemetic? A meta-analysis of published and unpublished randomized trials. Anesthesiology. 2004 Dec; 101(6):1454-63.

10 Joo J, Park YG, Baek J, Moon YE. Haloperidol dose combined with dexamethasone for PONV prophylaxis in high-risk patients undergoing gynecological laparoscopic surgery: a prospective, randomized, double-blind, dose-response and placebo-controlled study. BMC Anesthesiol. 2015 Jul;15(1):99.

11 Myklejord DJ, Yao L, Liang H, Glurich I. Consensus guideline adoption for managing postoperative nausea and vomiting. WMJ. 2012 Oct;111(5):207-13
12 Barton MD, Libonati M, Cohen PJ. The use of haloperidol for treatment of postoperative nausea and vomiting - a double-blind placebo-controlled trial. Anesthesiology. 1975 Apr; 42(4):508-12.

13 Metzger E, Friedman R. Prolongation of the corrected QT and torsades de pointes cardiac arrhythmia associated with intravenous haloperidol in the medically ill. J Clin Psychopharmacol. 1993 Apr;13(2):128-32.

14 Dağtekin $\mathrm{O}$, Wiese $\mathrm{P}$, Wolter K, Hermann MM, Pietruck C, Kampe S. Haloperidol versus haloperidol plus ondansetron for the prophylaxis of postoperative nausea and vomiting after ophthalmologic surgery. Pharmacology. 2009;83(4):205-10.

15 Brettner F, Janitza S, Prüll K, Weninger E, Mansmann U, Küchenhoff $\mathrm{H}$, et al. Genderspecific differences in low-dose haloperidol response for prevention of postoperative nausea and vomiting:a register-based cohort study. PLoS One. 2016 Jan;11(1):e0146746.

16 Pradeep R, Amitha S, Srinivasan KV. Comparison of haloperidol with ondansetron in preventing post-operative nausea and vomiting after laparoscopic abdominal surgeries. Indian Journal of Clinical Anaesthesia. 2016 $3(4): 562-7$.
17 Yazbeck-Karam VG, Siddik-Sayyid SM, Barakat HB, Korjian S, Aouad MT. Haloperidol versus ondansetron for treatment of established nause and vomiting following general anesthesia: A randomized clinical trial. Anesth Analg. 2017 Feb;124(2):438-44.

18 Honarmand A, Safavi M, Khalili G, Mohammadnejad F. Prophylactic administration of haloperidol plus midazolam reduces postoperative nausea and vomiting better than using each drug alone in patients undergoing middle ear surgery. Saudi J Anaesth. 2012 Apr; 6(2):145-51.

19 Aghadavoudi O, Mirkheshti M. Evaluating the effect of intravenous Haoperidol and Midazolam on post-operative nausea and vomiting after strabismus surgery. Majallah-i Danishkadah-i Pizishki-i Isfahan. 2014;32(281):470-6.

20 Chaparro C, Moreno D, Ramirez V, Fajardo A, Gonzalez D. Haloperidol as prophylactic treatment for postoperative nausea and vomiting. Rev Colomb Anestesiol. 2013;41(1):34-43.

21 Chu CC, Shieh JP, Tzeng JI, Chen JY, Lee Y, Ho ST, et al. The prophylactic effect of haloperidol plus dexamethasone on postoperative nausea and vomiting in patients undergoing laparoscopically assisted vaginal hysterectomy. Anesth Analg. 2008 May;106(5):1402-6. 